\title{
Energy saving prospectives of combined heat and power in horticulture in the Netherlands: a simulation study
}

\section{H.F. DE ZWART ${ }^{1 *}$ AND G.P.A. BOT ${ }^{1,2}$}

' DLO Institute of Agricultural and Environmental Engineering (IMAG-DLO), P.O. Box 43, NL-6700 AA Wageningen. The Netherlands

2 Department of Agricultural Engineering and Physics, Wageningen Agricultural University, Bomenweg 4, NL-6703 HD Wageningen, The Netherlands

*Corresponding author (fax: +31-317476439; e-mail: h.f.dezwart@imag.dlo.nl)

Recieved 27 September 1996; accepted 14 March 1997

\begin{abstract}
This paper studies the prospectives of the application of reject heat from on-site combined heat and power generation as a function of a number of horticultural characteristics. Especially the consequences of $\mathrm{CO}_{2}$-dosing with exhaust gases is studied. All computations are made with a recently developed dynamic simulation model describing the energy consumption of a greenhouse and the performance of its heating system as a function of outside weather conditions and horticultural requests of growers in the Netherlands.
\end{abstract}

Keywords: greenhouse climate simulation, combined heat and power, $\mathrm{CO}_{2}$ dosing

\section{Introduction}

Greenhouse horticulture is responsible for about $6 \%$ of national energy consumption in the Netherlands. Although its demand for electricity gains importance, still the largest portion of energy consumption in horticulture (about $90 \%$ ) concerns heat (Van der Velden et. al., 1996). Because of its large demand for heat, in principle horticulture is very suitable to apply reject heat from electricity production. The application of this reject heat boosts the conversion efficiency of primary fuel to exportable energy and is therefore a positive development. The overall result depends strongly on the choises on the heating capacity of the reject heat source and the fact whether or not the exhaust gases of the boiler are used to increase the greenhouse air $\mathrm{CO}_{2}$-concentration.

When using reject heat in horticultural practice in the Netherlands the heat either originates from an on-site combined heat and power engine (CHP-engine) or from a regional medium size power plant (some $20 \mathrm{MW}$ electric power). This paper focusses on the first type of reject heat application.

An important characteristic of the application of combined heat and power is that 
the control system of the greenhouse considers this heat source as the primary one. However, in case $\mathrm{CO}_{2}$ is obtained from exhaust gases from the boiler this preference conflicts with the necessity to carry off heat from the boiler during periods with a $\mathrm{CO}_{2}$-demand. In horticultural practice this conflict is solved by discarding the priority of the CHP-engine during periods with $\mathrm{CO}_{2}$-supply. The second important characteristic of combined heat and power is that the instantaneous heating power of the device is commonly chosen to be (much) less than the maximum heat demand in order to keep the investments at an acceptable level. In this paper the consequences of these characteristics will be shown by presenting their effects on the performance of the devices. energy consumption and biomass procduction level.

To be able to study the performance and prospectives of CHP as a function of horticultural characteristics a dynamic computer model was developed. Besides the simulation of the greenhouse climate, the model describes the dynamic behaviour of the heating system. The heating system includes a boiler, a reject heat source and a short term heat storage tank. The behaviour of the heating system is computed with a resolution in time up to two minutes. Thus the computer model acts as a virtual greenhouse on which new concepts of heating system engineering or control can be tested. Since the model is recently described thorougly and integrally (De Zwart, 1996), in this paper only the outlines of the model are sketched.

To judge the performance of the heating system and control the customary way of growing tomatoes in the Netherlands serves as the horticultural context. To show the sensitivity of the results, a number of cases are studied, differing with respect to thermal power of the CHP-device, the ability to purify the engine exhaust gases and the control of the device.

\section{Materials and methods}

\section{Greenhouse simulation model}

The simulation model is a lumped parameter model calculating the relevant state variables as a function of time from the greenhouse properties, the crop characteristics, the control setpoints and the varying outside weather conditions. This enables the calculation of energy consumption and crop production. The basis of the model are the energy and mass (water vapour and $\mathrm{CO}_{2}$ ) balances over the considered lumped parts of the system, resulting in a set of coupled, non-linear. first order differential equations that are solved numerically.

Since the greenhouse climate controller can be considered as the actuator that eventually determines the energy consumption of a greenhouse, the simulation model has been developed starting at the climate controller. Greenhouse air is one lumped component and its temperature, humidity and $\mathrm{CO}_{2}$ concentration are considered as primary state variables. The greenhouse climate controller compares their values with setpoints. The setpoints are functions of time and outside weather and are considered to be parameterized by the grower. Based on these comparisons the controller: 
- Adjusts the position of the mixing valve of the hot water supply to change the temperature of the heating pipes. In general the temperature of two separate heating systems are considered, one with pipes near the soil surface known as the lower heating system and one with pipes just above crop level, known as upper heating system.

- Adjusts the position of the ventilating windows for ventilation i.e. heat and mass exchange between the greenhouse air and the outside air.

- Opens and closes the thermal screen.

- Starts and stops the $\mathrm{CO}_{2}$ supply to the greenhouse air.

Besides the greenhouse climate, the controller controls the heating devices producing hot water (boiler, reject heat source and storage tank) and the $\mathrm{CO}_{2}$ production by the boiler or combined heat and power engine.

The controller actions have direct or indirect implications on the fuel consumption. This is obvious for the increment of the heating pipe temperature, although the fuel to serve this heat demand can be combusted hours earlier and temporary stored in a heat storage tank. The decision of the controller to turn on the CHP-engine or the boiler affects the conversion efficiency of natural gas to applicable heat. Opening ventilators has an energy consuming effect when this controller action originates from the humidity setpoint during periods of energy demand. Finally, $\mathrm{CO}_{2}$ supply induces fuel consumption in case the $\mathrm{CO}_{2}$ is obtained from exhaust gases from the boiler or CHP-engine during periods without energy demand.

Because the heat distribution system in greenhouses in the Netherlands is commonly a hot water filled pipe circuitry with a large thermal capacity and a typical cooling down characteristic, special attention is paid to the desription of its dynamic behaviour (De Zwart, 1996). The heat storage tank with its huge thermal capacity is modelled by an extensive multi-layer model according to the principles presented by Yoo and Pak (1993).

Besides the greenhouse climate controller the greenhouse air conditions depend on the heat and mass transfer between the greenhouse air and its direct environment. To describe these interactions the model distinguishes lumped components for the canopy, the floor, the thermal screen and the greenhouse cover. The soil under the floor represents a large heat storage capacity with a strong damping effect on greenhouse air temperature fluctuations. For a proper representation of this effect the soil is composed of seven layers. The cover is an important barrier for heat loss to the outside air. Moreover, when the cover temperature is below the dew-point of the greenhouse air, the cover surface adds to dehumidification of the greenhouse. The canopy surface is important with respect to heat release (gained from the sun), but even more with respect to the evaporation and the $\mathrm{CO}_{2}$ intake.

The outside weather conditions act as boundary conditions of the model. In Figure $I$ all previously mentioned state variables of the considered components and the boundary conditions are represented schematically. The state variables $T_{\text {top }}, V P_{\text {top }}$ and $\mathrm{CO}_{2}$ op are computed when the thermal screen is used only. When the screen is opened this air volume is lumped into the greenhouse air.

The outside air temperature and the sky temperature affect the convective and radiative heat losses at the cover and therefore the cover temperature. Outside tempera- 


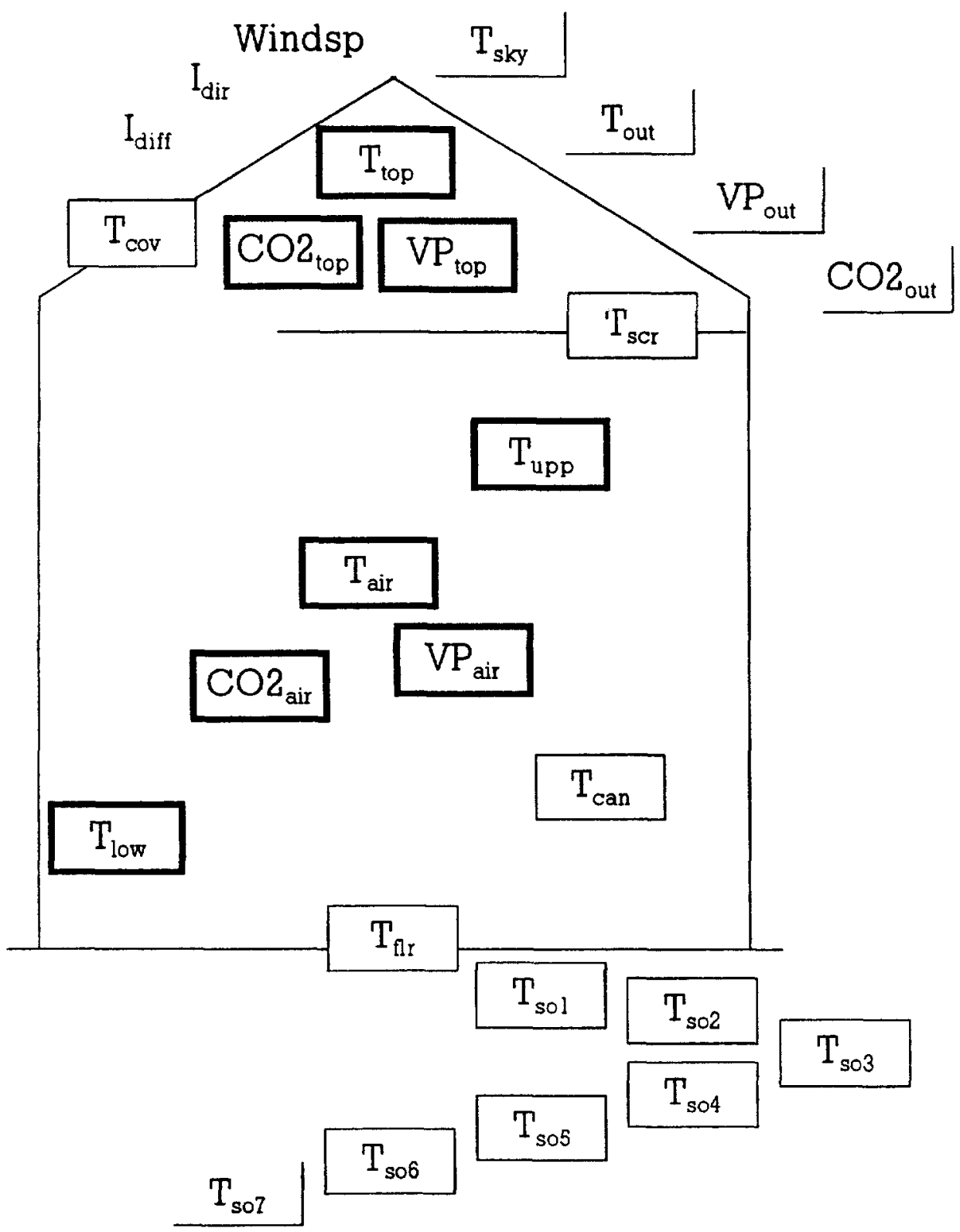

Figure 1. State variables and boundary conditions in the simulation model

ture. humidity and $\mathrm{CO}_{2}$ concentration have a direct implication on the primary state variables by air exchange through opened windows and cracks, as mentioned before. The wind speed is an important indirect weather condition because it affects the con- 
vective heat exchange at the cover and largely determines the air exchange rate through windows. An important weather condition is the global radiation. Direct and diffuse solar radiation are absorbed, reflected and transmitted by the cover, by the canopy and by the soil surface. Moreover, radiation at crop level is essential for photosynthesis.

To calculate the heat and mass fluxes between the lumped components, heat transfer relations are derived from a number of authors. The thermal radiation was calculated applying relations based on the Stefan-Boltzmann law, incorporating view factors, absorbtivity and emissivity (e.g. Pitts \& Sissom, 1986). Interception of solar radiation by the canopy was treated according to the work of Goudriaan (1977). The transmission of light through the cover was computed with a calculus presented by De Zwart (1993). The convective heat exchange at the inner and outer side of the cover was described by the relations presented by Bot (1983). The convective heat exchange at the inner side of the cover and at the thermal screen was thoroughly studied by Balemans (1989). The ventilation flux, in the horticultural context of the Netherlands typically based on natural ventilation, is computed with the theory presented by De Jong (1990). The canopy evaporation, a very important part of the model, is determined from the work of Stanghellini (1987). The convective heat release from heating pipes can be found in, again, the work of Bot, as can information on the convective heat exchange at the floor. The conduction of heat in the soil was treated with general heat conduction theory.

Due to the complexity and non-linearity of the model, the integration of the differential equations is performed by numeric forward integration. The step size is chosen such that the temperature change of the state variables is less than $0.1^{\circ} \mathrm{C}$. This means that the progress in time per integration step is often not more than 15 seconds. However, when outside weather conditions and climate controller actions are steady, the integration step size increases towards 2 minutes, which is the climate controller sample interval.

Comparison of the results of the model with measurements in a semi-practical greenhouse (four compartments of $200 \mathrm{~m}^{2}$ each) showed a very good resemblance. Absolute differences between model and measurements for the air temperature for 10 -minute mean values were less than $0.5^{\circ} \mathrm{C}$ for $90 \%$ of the time. Heat consumption was simulated with an accuracy of $95 \%$ and the control actions with respect to window aperture control and $\mathrm{CO}_{2}$-supply showed a good similarity (De Zwart, 1996)

\section{Horticultural context}

The overall performance of combined heat and power strongly depends on the context of application. In this paper, this context is created by the definition of a one hectare Venlo-type greenhouse growing tomatoes in the Netherlands.

The greenhouse is exposed to weather typical for the Netherlands. Such a set of data can be found in the SEL-year (Breuer \& Van De Braak, 1989). This set of weather data represents the mean weather in the Netherlands but preserves the full diurnal dynamics. This is achieved by selecting the data from a number of real weather data for each of the twelve month's of the year. The monthly mean tempera- 
ture and the mean daily radiation per month of the SEL-year data are shown in Figure 2.

The growing season in the reference greenhouse starts in December when the young tomato plants are planted. During the first three weeks the daytime and nighttime temperature setpoints are $18^{\circ} \mathrm{C}$. In case the solar radiation exceeds $100 \mathrm{Wm}^{-2}$ the air temperature sepoint is increased with $0.02{ }^{\circ} \mathrm{C}$ per $\mathrm{Wm}^{-2}$ excess until a maximum increment of $2^{\circ} \mathrm{C}$ is reached (at an outside global radition leven of $300 \mathrm{Wm}^{-2}$ ).

From sunrise to one hour before sunset the greenhouse air $\mathrm{CO}_{2}$-concentration is increased by adding exhaust gases from the boiler or, providing the exhaust gases are purified, from the CHP-engine. The maximal $\mathrm{CO}_{2}$ production of the boiler is $142 \mathrm{~kg}$ per hour which is realized by the combustion of $80 \mathrm{~m}^{3}$ of natural gas per hour. In case the $\mathrm{CO}_{2}$ originates from the CHP-engine the maximal rate is $142 \mathrm{~kg}$ as well because the purification device is chosen to be built at that capacity. In case the concentration exceeds $800 \mathrm{vpm}$, which is easily the case when the windows are closed, the $\mathrm{CO}_{2}$-addition is decreased. In case the $\mathrm{CO}_{2}$ production of the $\mathrm{CHP}$-engine is less than $142 \mathrm{~kg}$ per hour, which is the case for small engines, if necessary, the boiler adds $\mathrm{CO}_{2}$ in order to reach the capacity of the $\mathrm{CO}_{2}$ dosing system.

During periods with a limited heat demand, the heat associated with the production of $\mathrm{CO}_{2}$ can easily exceed the demand. In that case the heat surplusses are temporarily stored in a heat storage tank of $100 \mathrm{~m}^{3}$. In case the storage tank is completely filled the $\mathrm{CO}_{2}$-supply is stopped.

The humidity setpoint is set to $85 \% \mathrm{RH}$. If the actual humidity in the greenhouse exceeds the setpoint the windows are opened proportional to the excess with $1^{\circ}$ window opening per percent excess of the RH. The windows are also opened when the air temperature exceeds the setpoint by $1^{\circ} \mathrm{C}$ (the dead zone). The opening angle is proportional to the excess, with $3^{\circ}$ per ${ }^{\circ} \mathrm{C}$ excess above the temperature setpoint plus

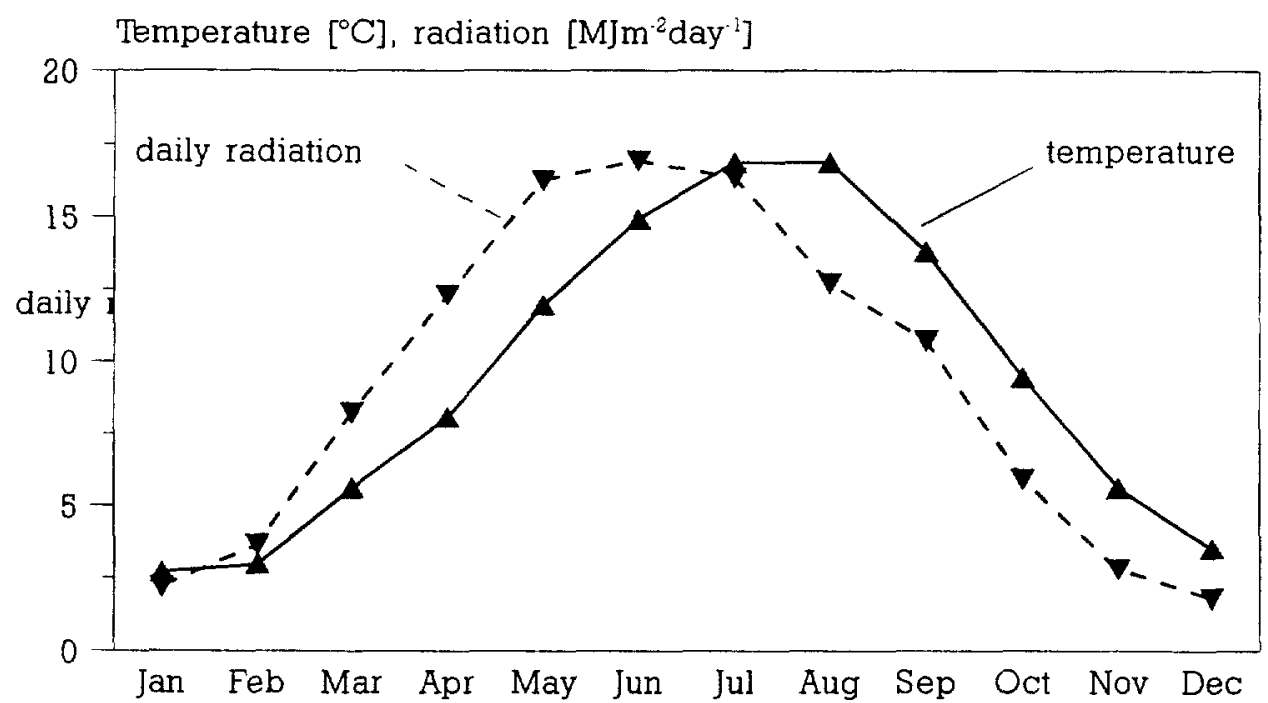

Figure 2. Typical monthly mean temperature and mean daily solar radiation level in the Netherlands. 
the dead zone. Windward side ventilators are opened only if the leeside ones have exceeded an aperture of $20^{\circ}$. The thermal screen is closed when the outside temperature drops below $10^{\circ} \mathrm{C}$, but opened with a slit of $8 \mathrm{~cm}$ in case the greenhouse air humidity exceeds $85 \%$ RH.

After the first period of three weeks the daytime temperature setpoint is increased to $19^{\circ} \mathrm{C}$ and the nighttime temperature setpoint is lowered to $17^{\circ} \mathrm{C}$. All other settings are left unaltered.

On the first of April the daytime and nighttime minimum pipe temperature are set at $45^{\circ} \mathrm{C}$ and $40^{\circ} \mathrm{C}$ respectively. The minimum pipe temperature acts as a threshold on the temperature of the lower heating pipe. During daytime, the minimum pipe temperature is lowered linearly towards the air temperature setpoint for outside global radiation in the range between 100 and $300 \mathrm{Wm}^{-2}$.

The growth season ends on 11 November. On that day the air temperature and minimum pipe temperature setpoints are lowered to $5{ }^{\circ} \mathrm{C}$. Humidity control and carbon dioxide supply are abandoned.

The Venlo-type greenhouse is built from a repeated sequence of $3.20 \mathrm{~m}$ wide roof segments. The building is composed of 30 of these roof segments. The gutter length of the greenhouse is 104 meter. The floor to gutter height is assumed to be 3.5 meter. One window per eight glass panels is mounted in each side of the greenhouse cover. The windows are $2 \mathrm{~m}$ wide and half the ridge-gutter distance long. The roof slope is $25^{\circ}$. When the windows are closed, the leakage of the greenhouse is assumed to be $1.25 \cdot 10^{-4} \mathrm{~m}^{3}$ per $\mathrm{m}^{2}$ greenhouse per unit wind speed $\left(\mathrm{ms}^{-1}\right)$. This figure is a mean of the leakages determined by De Jong (1990) in four commercial greenhouses.

The heating system consists of primairy heating pipes of $51 \mathrm{~mm}$ located near the floor and an overhead secondary heating system of $28 \mathrm{~mm}$ pipes. With four pipes per roof segment near the floor and half as much overhead pipes, the maximum heating power of the heating system, if fed with $90^{\circ} \mathrm{C}$, is about $240 \mathrm{~W} / \mathrm{m}^{2}$. The secondary heating pipes accompany the primary heating pipes in case the temperature of the latter exceeds $60^{\circ} \mathrm{C}$.

\section{Computations}

With the application of on-site CHP-engines in horticulture, besides the production of vegetables and flowers, greenhouses become producers of marketable electricity. This activity raises the primairy fuel consumption of the greenhouse-site. However, because the electricity produced by CHP replaces electricity production of public power plants that, as a rule, do not use their reject heat, the overall energy conversion efficiency of the fuel increases.

The net effect of CHP depends on the conversion efficiencies of the heat and electricity production processes. At the moment, the conversion efficiencies of pistonengine based CHP-devices have typical conversion efficiencies of 0.38 for electricity and 0.52 for heat (both figures hold for the lower heating value of natural gas). This means that every MJ of thermal energy produced by CHP requires $1.92 \mathrm{MJ}$ of primairy energy and is accompanied by $0.73 \mathrm{MJ}$ of electric energy. Since the typical conversion efficiency of primary fuel to heat of horticultural boilers is much higher 
( 0.95 with respect to the lower heating value) the production of heat by a CHP-device consumes $0.89 \mathrm{MJ}$ extra fuel per $\mathrm{MJ}$ thermal energy. However, because the 0.73 MJ electricity produces replaces the electricity of public power plants with a typical electric conversion efficiency of 0.5 (with respect to the lower heating value) the extra primary fuel consumption is more than compensated by a primary fule saving of $1.46 \mathrm{MJ}$ at the public power plant. Thus the net effect of the production of heat by a CHP-engine instead of a boiler is $0.57 \mathrm{MJ}$ per MJ.

In order to determine the effect of the application of CHP-engines in a horticultural context the year round heat production of such an engine is determined by the greenhouse simulation model for various thermal power levels and regimes of $\mathrm{CO}_{2}$ supply. The results of these model evaluations are presented in the next section.

\section{Results}

Simulation runs were made to study the interaction of thermal power and year round heat and electricity production of CHP-engines. The results were compared with a situation where the greenhouse is not equipped with CHP. To study the effect of thermal power the computations were made with thermal power levels of 16,32 and 48 $W_{\text {th }}$ per $\mathrm{m}^{2}$ greenhouse. To get an impression of the contribution of CHP the mean daily heat production of the engines, together with the mean daily heat demand of the greenhouse is shown in Figure 3.

Figure 3 clearly shows that the heat production of CHP in summer is seriously diminished by the reject heat from the boiler when producing $\mathrm{CO}_{2}$. Another reason, for heat production of the boiler instead of the CHP-engine, but much less dominating, is the peak heat demand in the morning hours which can be far much larger

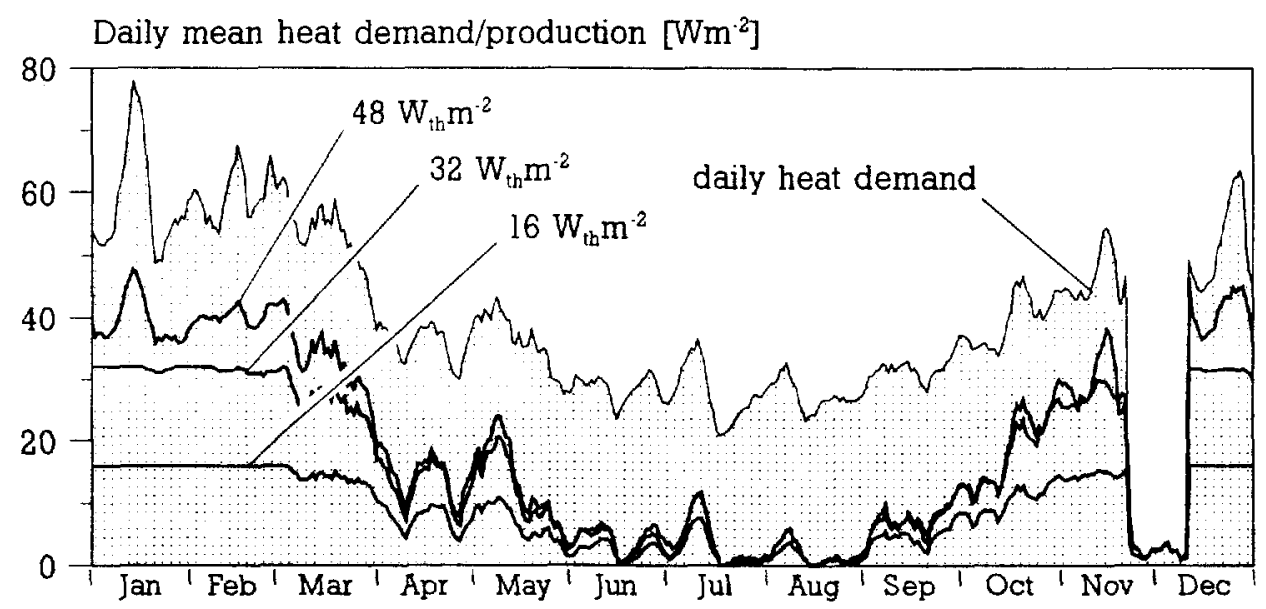

Figure 3. Mean daily heat demand of the greenhouse and heat production of a CHP-engine without exhaust purification for three thermal power levels (the values are smoothed by a 10 cell moving average filter). 
Daily mean heat demand/production $\left[\mathrm{Wm}^{-2}\right]$

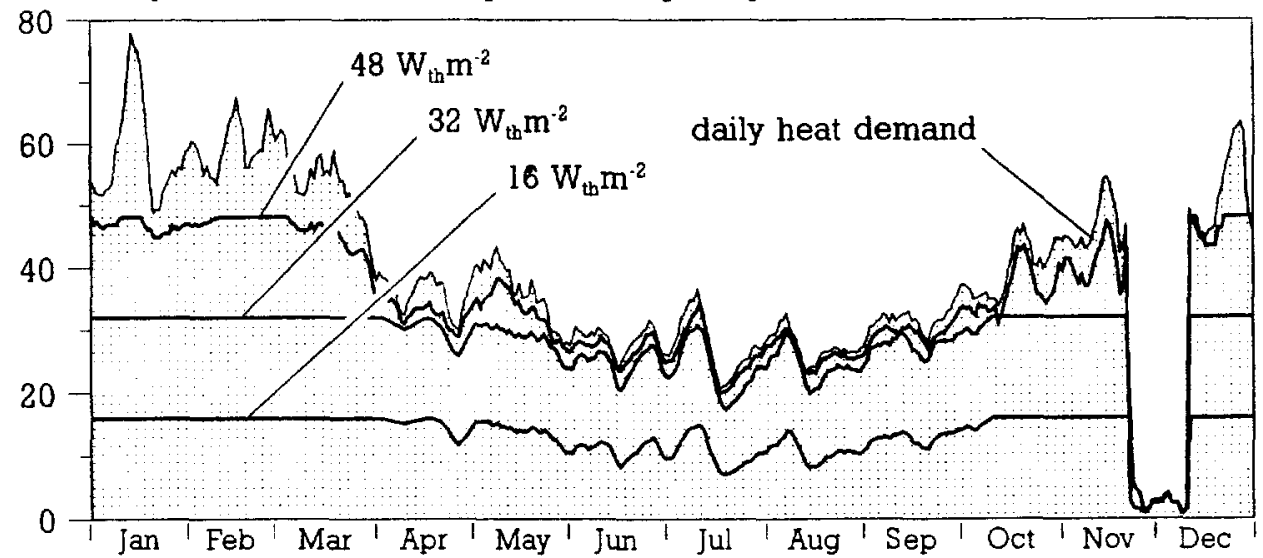

Figure 4. Mean daily heat demand of the greenhouse and heat production of a CHP-engine with an exhaust purification device for three thermal power levels (the values are smoothed by a 10 cell moving average filter).

than the thermal power of the CHP-engine, even on days with a small mean heat demand.

To study the effect of attempts to solve these two problems that decline the potential of CHP, the model was equipped with an exhaust purification device and with an adapted CHP-controller. The exhaust purification device enables to limit the use of the boiler for $\mathrm{CO}_{2}$-production to only those periods where the $\mathrm{CO}_{2}$-supply from $\mathrm{CHP}$ cannot meet the demand of the greenhouse. In order to reserve heating power for periods with a peak demand, the adapted CHP-controller aims to keep part of the storage tank at $90^{\circ} \mathrm{C}$. During the cold period of the year (Oct up till April) this amount is $50 \mathrm{~m}^{3}$ ( $50 \%$ of the heat storage tank). During the other months of the year the peak demands are much smaller, which enables to size the charged volume of the storage tank down to $25 \mathrm{~m}^{3}$.

The comparison of Figure 4 with Figure 3 shows the enormous effect of exhaust gas purification in summer. It appears that small CHP-devices can run almost all year long at full capacity. The fact that the small dips in the curves for the $32 \mathrm{~W}_{\mathrm{th}} / \mathrm{m}^{2}$ device in the winter period in Figure 3 are less in Figure 4 is a result of the adapted control. The adapted control is also responsible for the increased contribution of the $48 \mathrm{~W}_{\mathrm{th}} / \mathrm{m}^{2}$ device in winter.

Table 1 shows the yearly totals of heat production by the boiler and the CHP-engine. The table shows that despite the increasing primary energy consumption at the greenhouse site, on a national scale, the application of CHP saves energy. Compared to the reference the maximal energy saving (with the $48 \mathrm{~W}_{\mathrm{th}} / \mathrm{m}^{2}$ CHP-engine) is $25 \%$. Obviously, the ability to clean the exhaust gases is of utmost importance in the final performance. Without a purifacation device the energy saving of the $48 \mathrm{~W}_{\mathrm{th}} / \mathrm{m}^{2}$ CHP-engine is limited to $17 \%$. The adaptation of the CHP-control improves its contribution to the greenhouse heat demand just a little. 
Table 1. Primary energy consumption and electricity export from a a nursery with CHP, a public power plant and the overall primary energy consumption related to $\mathrm{a}^{2}$ greenhouse producing tomatoes and the production of $790 \mathrm{MJ}$ of electric energy for several thermal power levels of a CHP-enigne with and without exhaust gas purification and for two CHP control strategies.

\begin{tabular}{|c|c|c|c|c|c|c|c|}
\hline & $\begin{array}{l}\text { Thermal } \\
\text { CHP } \\
\text { power } \\
\mathrm{w}_{\mathrm{th}} / \mathrm{m}^{2}=\end{array}$ & $\begin{array}{l}\text { Greenhouse } \\
\text { heat } \\
\text { demand } \\
\text { Gjm }^{-2 y r} r^{-1} \\
\text { heat prod. }\end{array}$ & $\begin{array}{l}\text { Fraction } \\
\text { from } \\
\text { CHP }\end{array}$ & $\begin{array}{l}\text { Greenhouse } \\
\text { primary } \\
\text { energy } \\
\text { demand } \\
G^{2} m^{2} \mathrm{yr}^{-1}\end{array}$ & $\begin{array}{l}\text { Electricity } \\
\text { export } \\
\text { Gjm- } \mathrm{yr}^{-1}\end{array}$ & $\begin{array}{l}\text { Power plant } \\
\text { primary } \\
\text { energy } \\
\text { demand } \\
\text { GJm ' } \mathrm{yr}^{-1}\end{array}$ & $\begin{array}{l}\text { Overall } \\
\text { primary } \\
\text { energy } \\
\text { demand } \\
\text { GJm-2yr-1 }\end{array}$ \\
\hline Reference & 0 & 1.22 & 0.00 & 1.29 & 0.00 & 1.58 & 2.86 \\
\hline \multirow{3}{*}{$\begin{array}{l}\text { No exhaust } \\
\text { cleaning, } \\
\text { standard } \\
\text { control }\end{array}$} & 16 & 1.22 & 0.22 & 1.43 & 0.20 & 1.18 & 2.61 \\
\hline & 32 & 1.22 & 0.41 & 1.58 & 0.36 & 0.85 & 2.43 \\
\hline & 48 & 1.22 & 0.49 & 1.65 & 0.43 & 0.71 & 2.36 \\
\hline \multirow{3}{*}{$\begin{array}{l}\text { Exhaust } \\
\text { cleaning, } \\
\text { standard } \\
\text { control }\end{array}$} & 16 & 1.22 & 0.34 & 1.52 & 0.31 & 0.96 & 2.49 \\
\hline & 32 & 1.22 & 0.71 & 1.89 & 0.63 & 0.31 & 2.20 \\
\hline & 48 & 1.22 & 0.85 & 2.09 & 0.76 & 0.06 & 2.15 \\
\hline \multirow{3}{*}{$\begin{array}{l}\text { Exhaust } \\
\text { cleaning, } \\
\text { adapted } \\
\text { control }\end{array}$} & 16 & 1.22 & 0.35 & 1.53 & 0.31 & 0.96 & 2.48 \\
\hline & 32 & 1.22 & 0.71 & 1.90 & 0.64 & 0.30 & 2.20 \\
\hline & 48 & 1.22 & 0.88 & 2.14 & 0.79 & 0.00 & 2.14 \\
\hline
\end{tabular}

\section{Discussion}

Electricity production by combined heat and power is an efficient way of producing this favourable form of energy. Consequently, in the Netherlands. governmental policy on the propagation of energy saving techniques heavily focusses on the application of this way of electricity production (Anonymous, 1992; Anonymous, 1995).

Until recently, in summer the application of this way of electricity production was strongly. limited because of the fact that the exhaust gases of combined heat and power engines were not suitable for $\mathrm{CO}_{2}$-dosing (De Zwart, 1996). To overcome this problem, a number of purification methods are being studied (Anonymous, 1994). Due to the intensive research, some of these purifiaction systems have become cheap and reliable enough to be used in greenhouses (Anonymous. 1996). Thus, besides the efficient application of reject heat, also the $\mathrm{CO}_{2}$ emission related to electricity production from fossil fuels can be applied in an efficient way. Apart from the benefits from increased electricity production at the greenhouse site. it can be expected that crop production will be enhanced as well. This because the amount of $\mathrm{CO}_{2}$ per unit of heat from a CHP-engine is almost twice compared to the case where $\mathrm{CO}_{2}$ is obtained from the boiler.

Together with recent possibilities to insure the canopy for damage caused by malfunctioning of the purification unit, combined heat and power in horticulture is ready for the next step ahead. 


\section{References}

Anonymous, 1992. Agreement between horticulture in the Netherlands and the government, represented by the Minister of Economic Affairs and the Minister of Agriculture, Nature Management and Fisheries, involving the improvement of energy conversion efficiency (In Dutch), Landbouwschap, The Hague, 19 pp.

Anonymous, 1994. Exhaust gas treatment for combined heat and power in horticulture (In Dutch), Studies en Diensten de Melker B.V., Margraten, 72 pp.

Anonymous, 1995. Third Energynote (In Dutch). Sdu Uitgeverij, The Hague, $199 \mathrm{pp}$.

Anonymous. 1996. $\mathrm{CO}_{-}$-dosing with exhaust gases of CHP-engines (In Dutch), Project-bureau Warmte'Kracht, Driebergen'Rijsenburg. 12 pp.

Balemans. L., 1989. Assessment of criteria for energetic effectiveness of greenhouse screens. Ph.D. Thesis, Gent Agricultural university, Gent, $157 \mathrm{pp}$.

Bot, G.P.A., 1983, Greenhouse climate: from physical processes to a dynamic model. Ph.D. Thesis. Wageningen Agricultural University, Wageningen, $240 \mathrm{pp}$.

Breuer, J.J.G. \& N.J. Van De Braak, 1989. Reference year for Dutch greenhouses, Acta Horticulturae 248: $101-108$.

De Jong, 1990. Natural ventilation of large multispan greenhouses. Ph.D. Thesis, Wageningen Agricultural University, Wageningen, $117 \mathrm{pp}$.

De Zwart, H.F. 1993. Determination of direct transmission of a multispan greenhouse using vector algebra. Journal of agricultural Engineering Research, 56:39-49

De Zwart, H.F., 1996. Analyzing energy saving options in greenhouse cultivation using a simulation model, Ph.D. Thesis, Wageningen Agricultural University, Wageningen, 238 pp.

Goudriaan, J., 1977. Crop micrometeorology: a simulation study. Simulation Monographs. Pudoc, Wageningen, $249 \mathrm{pp}$.

Pitts, D.R. \& L.E. Sissom, 1986. Heat transfer. Schaum, Singapore, 325 pp.

Stanghellini, C.. 1987, Transpiration of greenhouse crops, an aid to climate management. Ph.D. Dissertation, Agricultural University, Wageningen, $150 \mathrm{pp}$.

Van Der Sluis, B.J., A.A. Rijsdijk, G.P.A. Van Holsteijn \& N.J.A. Van Der Velden, 1995. The application of thermal screens in tomato (In Dutch). Agricultural Economics Institute (LEI-DLO), The Hague, 76 pp.

Van Der Velden. N.J.A., B.J. Van Der Sluis and A.P. Verhaeg, 1996. Energy in horticulture in the Netherlands; developments in the sector and at the nurseries up till 1995 (In Dutch). Agricultural Economics Institute (LEI-DLO), The Hague, $76 \mathrm{pp}$.

YOO H. \& E. Pak. 1993. Theoretical model of the charging process for stratified thermal storage tanks. Solar Energr: 51: 513-519 